\title{
Study on Improving Engineering Information Management by Integrating BIM and Internet of Things ${ }^{+}$
}

\author{
Yanyu Meng ${ }^{1, \mathrm{a}}$, Nan $\mathrm{Wu}{ }^{1.2, \mathrm{~b}}$, Hui Pang ${ }^{1, \mathrm{c}}$ and Fan Yang ${ }^{1, \mathrm{~d}^{*}}$ \\ ${ }^{1}$ College of Transportation and Civil Engineering, Beihua University, Jilin 132000, china \\ ${ }^{2}$ Forestry College, Beihua University, Jilin 132000, china

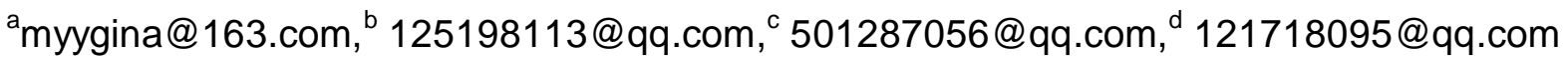 \\ ${ }^{*}$ Corresponding author
}

Keywords: BIM; Internet of Things ${ }^{+}$; Engineering Information; Project Management

\begin{abstract}
With the continuous and rapid development of the economy as well as the scientific information technology in China, the construction industry has ushered in a new market as a very prominent part of the national economic system. Under the background of the rapid development of both science and technology, informatization has been closely related to people's lives, which has gradually penetrated into various industries. Information management of construction projects has become an irresistible trend. Therefore, studying on the topic of how to apply modern information technology to improve engineering information management will be of pivotal significance to the construction industry. This paper will talk about the characteristics as well as the advantages of the integration of BIM and Internet of Things as well as the technology so as to further talk about its effect on improving engineering information management.
\end{abstract}

\section{Engineering Management Informatization}

The Significance of Engineering Management Informatization. In the course of the implementation of a construction project, a large amount of information data will be generated. Therefore, the transmission and exchange of these data information will become a very important part of the engineering project management process. In the traditional engineering project management process, various information on the project is mainly reflected in paper forms such as forms, bills, contracts, pictures, etc.[1-3]. In this mode, the management personnel are required to go through information searching and artificial transmission, which require a great deal of time, and can not guarantee that information transmission errors will not occur. Thus, it will pose a security risk to the quality of construction projects. The application of information technology to manage the construction project can be a clever way to solve the above problems and generate more value.

To begin with, the application of information technology software, such as BIM, can integrate and refine all the information data of an engineering project. Managers can use it to obtain the required data, and if it is necessary to improve a certain construction process. Managers can use scientific information technology to directly deliver instructions to workers through mobile devices. This process saves time compared to traditional management processes and improves the accuracy and security of information transmitted.

In short, compared with the traditional project management mode, the information management of construction engineering has obvious advantages in collecting, organizing and transmitting information. What's more, it can also save time, save human resources and is safe as well as convenient.

The Necessity of Construction Engineering Informatization. In the era of rapid industrialization, the importance of environmental protection cannot be ignored along with the construction. The voice of green building is getting more and more affirmative response in the construction industry while the application of information management greatly promoted its sustainable development.

In the construction process of an engineering project, it is crucial for a manager to closely follow the trend, master modern management methods and have advanced management concepts. Judging from 
the immediate situation, combined with the current development, information management has become an inevitable trend in the development of the building [4-5], BIM technology is particularly important in the process of engineering management information.

\section{BIM Technology and Information Management}

The Role of BIM Technology in Engineering Management. BIM technology has created a technological revolution in the construction industry because it completely overturns the traditional architectural design concept, project cost model, and construction model. It uses digital technology to express various physical and functional characteristics of the project, enabling it to share data and provide a digital basis for decision making. To conclude, this digital technology makes the traditional database complete and consistent with the actual situation [6].

In the era of information, BIM technology is an important tool for engineering management informationization. By using BIM technology, we can realize the information management of the entire construction life cycle from the design phase to the operation and maintenance phase.

A complete BIM model is actually a complete representation of the underlying data in an engineering project. Digitization is its foundation and its core concept. We can almost say that the emergence and development of BIM technology have opened up the information management of construction projects and is a milestone in the construction industry. Of course, at the same time, there are also areas in which current BIM technologies can be used to further their value.

Current Application Situation of BIM Technology. Currently, people have made full use of the advantages of 3D model in BIM application, which has provided great convincing to both designers and constructors. For example, during the design process, the designer can find out which part is unreasonable and can take corrective measures in time by simulating collision detection, so as to eliminate unnecessary construction costs and the consumption of talented machinery. For construction workers, it is more intuitive to understand the construction method of a specific process, which can help to avoid the occurrence of many errors, indirectly save time and improve the quality of the project. However, because most managers pay too much attention to the BIM model itself, the application of the BIM model in terms of construction and operation is ignored. Coincidentally, $75 \%$ of the cost of a building's life cycle occurs in the operation and maintenance phase (using Phase): The cost of the construction phase (design, construction) accounts for $25 \%$ of the life cycle cost of the project. In the construction phase, the construction and construction cost is also much higher than the design [7]. Therefore, how to best apply the BIM technology to the engineering project operation and maintenance phase management is worthy of deep thinking in the construction industry.

The most significant characteristic of BIM technology is flexibility. It can make the information transmission among workers more convenient, and the staff can view the data information and construction process of any component at any time through the BIM model, and can also see the geographical location of overall construction project. A small problem with what is otherwise perfect is that we can't understand the relationship between components and components in real time through the BIM model, and we can't even realize the monitoring of the construction process. That is to say, there is a lack of connection between various small objects in this large object under the BIM model. Therefore, in the management of construction, operation and maintenance, how to connect these isolated parts becomes a breakthrough in improving the management of engineering information. The method that can solve this problem the emerging advanced technology- Internet of Things.

\section{Internet of Things ${ }^{+}$}

The Concept of Internet of Things. The simple understanding of Internet of Things is connected objects, which has two meanings [8-9]: first, the Internet is still the core and foundation of the Internet of Things, and the Internet of Things uses the Internet to expand and extend; Second, the Internet of Things terminals can be extended and extended to any item that utilizes relevant technology to facilitate intelligent information exchange and communication via the Internet. 
Technical Framework of Internet of Things. The technical framework of the Internet of Things has three main aspects: perception technology, network technology and applied technology. The core technologies of the Internet of Things include Radio Frequency Identification (RFID) and Wireless Sensor Technology (WSN).

The sensing technology of the Internet of Things mainly includes the sensor technology, RFID technology and the coordinate positioning technology. Sensor technology is widely used in modern society. There are numerous sensor settings in cars that come into contact with everyday life. From industrial production to small household appliances, all automation is inseparable from sensor devices. And RFID is radio frequency identification, which is what we often call inductive electronic chip. Its application in daily life is simply an electronic tag attached to the surface of an object. In this way, the reader in the computer can sense electronic tags and identify the data, and further transmit information to the computer terminal and further processing. The coordinates positioning technology, we all know about is GPS positioning system and there is no need to introduce more.

The Internet of Things network technologies include low-power consumption near-distance wireless, IPV6, wide-area wireless access enhancement, and gateway technologies; the application technologies of the Internet of Things include data storage, parallel computing, data mining, and platform service and information presentation in daily life.

Current Application Situation of Internet of Things. The BIM Internet of Things technology is considered as a great revolution in the information age in the 21st century. The application of Internet of Things technology in traditional industries will greatly promote the development of social economy.

Today, many developed countries such as the United States and Japan attach great importance to the development of Internet of Things technology. Compared with these developed countries, our country is not behind in the application and development of the Internet of Things technology. China Mobile, China Telecom and other operators are actively carrying out research work on the Internet of Things technology and have achieved corresponding research results. In general, the Internet of Things technology has been integrated with the informationization of diverse industries in life. At the same time, the government's strong support and vigorous promotion have also created unprecedented opportunities for China's Internet development.

Of course, lots of problems have occurred when Internet of Things is getting developed and mature. For example, there is no unified technical standard. However, the immense convenience brought by the Internet of Things cannot be ignored, and especially the integration of BIM and IoT will inevitably create a non-negligible asset under the development trend of green buildings.

\section{Integration of BIM and Internet of Things}

The Connotation of BIM and Internet of Things Integration. The integrated application of BIM technology and IoT technology is essentially the integration of information in the entire construction process [10-12]. Its meaning is to make use of the respective technical features and advantages of BIM and IoT, and to combine the two in a place where the technologies are similar or complementary. The technology can be applied to each other and make full use of the advanced technology of the Internet of Things to make up for the defects and deficiencies of BIM as a single technology, so as to increase the value of the BIM tool in the construction industry and promote the green building and smart city. Development will open up a new path for the sustainable development of the construction industry.

Turning Point for Integrating BIM Technology and Internet of Things. BIM refers to building information model which is used in the construction industry to truly present attributes such as the shape of a building project. By taking advantage of this characteristic, we can use BIM technology to carry out collision detection and pipelines and simulation calculations etc. so as to fully protect the entire building's safety construction [13]. In the simulation process, the information exchange of each participant is realized, which is a collaborative design as we know. Because of these functions, we use BIM in the collaborative management of the entire life cycle of the construction project and realize the information management of the construction project. 
However, during the entire life cycle of a construction project, the participating units include the engineering designer, the general contractor, the engineering subcontractor, the engineering supervisor, and the project builder. These participants perform their own duties and work in different ways. Therefore, the work is highly decentralized, and mobile [14], which also triggered new requirements for the BIM application such as site-specification, mobility, real-time etc. and then IoT is proposed. The implementation of radio frequency technology and wireless sensor technology of the Internet of Things can eliminate obstacles in the information exchange of each participant in the project management process, thus effectively connecting the BIM and relevant staff. Only in this way can we enable the participants to communicate well with each other in the life cycle management of the project, and prevent the occurrence of mistakes in project management caused by the lack of work exchange and independent work among the participants.

Advantages of Integrating BIM and Internet. The technical framework of IoT has been mentioned in the foregoing part and the following will be focusing on the integration of key technologies of IoT and BIM.

In the Internet of Things, RFID refers to radio frequency identification. Its most important feature is electronic tag. In the course of engineering management, we can allocate key materials and key facilities and equipment for important construction workers to their respective RFIDs. With electronic tags and GPS positioning systems, engineering managers can detect the location and status of these important components in real time, which directly increases the timeliness of information management for managers in the management process. Besides, with the wireless sensor technology and the alarm system, we can discover the occurrence of abnormal phenomena in the construction process at any time and greatly reduce construction risks.

Value Outlook for the Integration of BIM and IoT. The advantage of integrating BIM with the Internet of Things is that it can connect all the objects involved in the construction management throughout the entire life cycle. Specifically, it takes advantage of the radio frequency identification and wireless sensing technology in the Internet of Things to build the reality in the construction project to connect the environment, the building, the BIM itself and the staff. In this way, the project management in the operation and maintenance phase will be safer and more efficient, as shown in Fig.1.

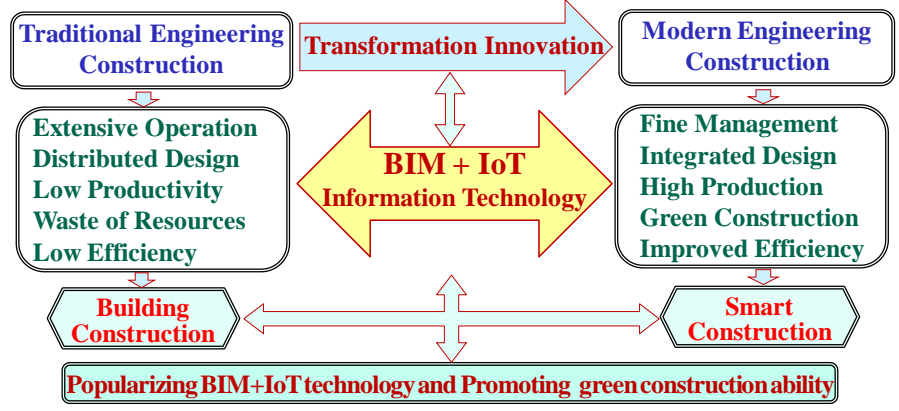

Figure 1. Trend of engineering informatization management

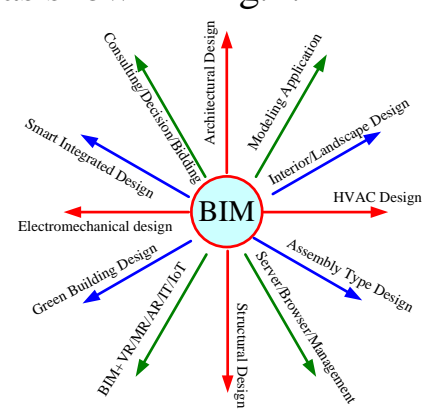

Figure 2. Integrating BIM and IoT $^{+}$

In addition, the integration of BIM technology and IoT technology can use intelligent terminal device to obtain the data in BIM and RFID. That is to say, after integrating BIM and IoT, we can directly monitor the location, structure, design parameters and construction process etc. of the tagged objects in the terminal mobile service so as to timely correct and formulate a corresponding construction plan and maintenance of different equipment. As shown in Fig2, once there is a certain instruction, the management personnel can directly notify the corresponding staff through the mobile device. The staff member can in turn view the corresponding data and conduct and this process can realize high-end engineering management informationization.

\section{Conclusion}

The information management of construction projects is a general trend. In the future development of the construction industry, green building is a necessary condition for the sustainable development of the 
construction industry. Therefore, it is imperative to use modern information technology to improve the engineering management information. Although the integration of BIM technology and IoT technology is still in its infancy, further exploration of information technology, the future integration of BIM technology and IoT technology will inevitably increase the informatization management of engineering projects and promote construction.

\section{Acknowledgements}

Supported by the 2016 Education Scientific Research Subject (No. YB201624 and No. YB201623) And by the 2017 Education Scientific Research Subject (No. 201708).

\section{References}

[1] Y.X. Wang. Existing problems and countermeasures in information management of construction project,J.Green Environmental Protection Building Materials, (2018) No.1, pp.200-200. (In Chinese)

[2] L.F. Ji. The Application and Research of BIM Technology in Sustainable Urban Construction, J. Jiangxin Building Materials, (2015) No.19, pp.121-121. (In Chinese)

[3] Y. Peng. Discuss on the Application of BIM and Internet of Things Technology Integration, J. Railway Technical Innovation, (2015) No.6, pp.45-47. (In Chinese)

[4] J. Liu and J.Q. Gu. The current situation and development strategy of Internet of Things in China, J. Enterprise Economy, Vol. 32 (2013) No.4, pp.114-117. (In Chinese)

[5] J.J. Lu, D.W. Wang, F.Z. Sun, Z.Q. Yi, and B. Yu. Intelligent building integrated management platform based on Internet of things and big data operation, J. Intelligent Building, (2017) No.4,pp.79-80. (In Chinese)

[6] J. Wang and Y.L. Jia. Application of BIM Technology in construction management, J. Architectural Engineering Technology and Design, (2017) No.26, pp.1901-1901. (In Chinese)

[7] D.F. Liu, G.Q.Chen, X.L. Zhang, X.D. Zhou and Q.S. Han. Application of information technology in construction quality management, J. Technology \& Market, Vol.24 (2017) No.12, pp.241-242. (In Chinese)

[8] J. P. Deng. Brief talk on construction management under the background of informatization, J.Construction Materials \& Decoration, (2017) No.50, pp.297-298. (In Chinese)

[9] L.H. Zhu, L. Sun. Study on BIM and virtual data space, J.Architecture Technique, (2017) No.9,pp.104-106. (In Chinese)

[10] C. Liu. Research on construction quality management method and control strategy, J.Technology Innovation and Application, (2018) No. 1, pp. 100-101. (In Chinese)

[11] Y. Zhao and Y.Z. Su. Study on smart city based on integration of cloud computing and Internet of Things, J. Education Forum, (2017) No.23, pp.80-81. (In Chinese)

[12] X. Chen. Information technology provides support for the sustainable development of construction industry, J. Information of China Construction, (2015) No.22,pp.32-33. (In Chinese)

[13] C. Merschbrock. Digital Collaboration in the Wood-based Construction Industry: Deployment of Building Information Modeling, D. University of Agder Faculty of Social Sciences, 2014.

[14]C.Z. Li, J. Hong, F. Xue, G.Q. Shen, X. Xu and L. Luo. SWOT analysis and Internet of Things-enabled Platform for Prefabrication Housing Production in Hong Kong, J. Habitat International,(2016) No.57,pp.74-87. 